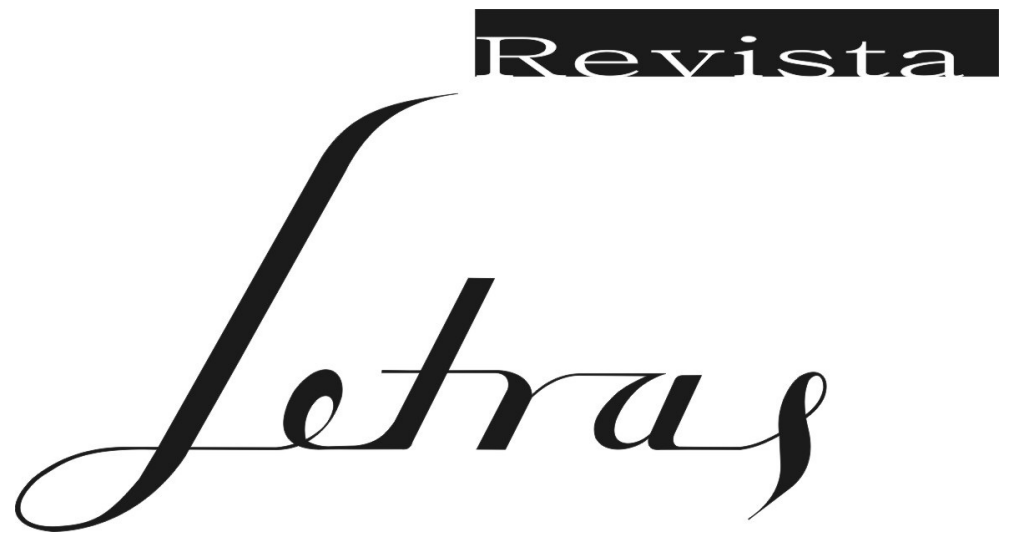




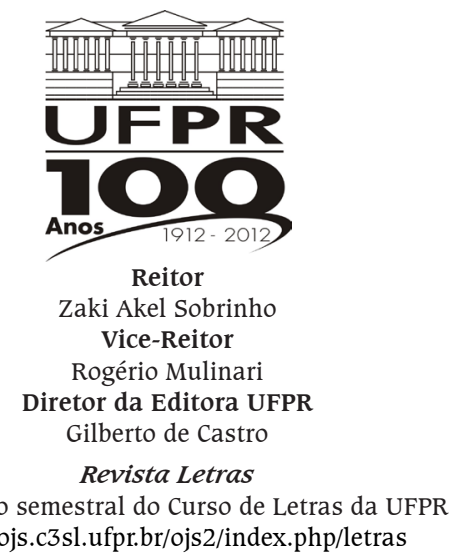

A Revista Letras está indexada nos seguintes índices bibliográficos: 1. Internationale Bibliographie der Rezensionen Wissenschftlicher Literatur/International Bibliography of Book Reviews of Scholarly Literature; 2. Linguistics and Language Behavior Abstracts;

3. MLA - International Bibliography of Books and Articles on Modern Languages and Literatures; 4. Social Planning, Policy and Development Abstracts; 5. Sociological Abstracts; 6. Ulrich's International Periodicals Directory; 7. CLASE-Citas Latinoamericanas en Ciencias Sociales y Humanidades.

Editora: Maria Cristina Figueiredo Silva (UFPR) Secretários editoriais: André Tadra Ribeiro e Simone Aparecida Schiavinato Editora da Seção de Estudos Linguísticos: Maximiliano Guimarães Editora da Seção de Estudos Literários: Marcelo Paiva

Conselho Editorial

Antonio Dimas (USP), Beatriz Gabbiani (Universidad de la República do Uruguai), Carlos Alberto Faraco (UFPR), Carlos Costa Assunção (Universidade de Trás-os-Montes e Alto Douro), Elena Godoi (UFPR), Filomena Yoshie Hirata (USP), Gilda Santos (UFRJ), José Borges Neto (UFPR), Júlio Cesar Valladão Diniz (PUC-RJ), Lígia Negri (UFPR), Lúcia Sá (Manchester University), Lucia Sgobaro Zanette (UFPR), Maria Lucia de Barros Camargo (UFSC), Marília dos Santos Lima (UNISINOS), Mauri Furlan (UFSC), Maurício Mendonça (UFPR), Raquel Salek Fiad (Unicamp), Rodolfo A. Franconi (Darthmouth College), Rodolfo Ilari (Unicamp)

\section{Consultores ad hoc}

Alessandro Boechat de Medeiros, Alessandro Rolim de Moura, Álvaro Faleiros, Ana Lúcia Oliveira, Ana Scher, Antonio Nery, Aparecida Bueno, Bruno Dallari, Caetano Galindo, Célia de Miranda, Cláudia Campos, Cristina Rodrigues, Fabíola Padilha, Fernando Gil, Francisco Fogaça, Germana Pereira, Gesualda Rasia, Guilherme Flores, Iara Costa, Isabel Jasinski, Juanito Avelar, Lígia Negri, Luiz Arthur Pagani, Marcelo Souza, Marcos Siscar, Maria Clara Oliveira, Maria Frota, Maria Viviane Veras, Márcia Martins, Mauri Furlan, Maurício Mendonça, Milena Martins, Mônica Figueiredo, Nylcéa de Siqueira Pedra, Paulo Sodré, Paulo Soethe, Raquel Bueno, Roberta Pires de Oliveira, Rodrigo Gonçalves, Rogério Lima, Roosevelt da Rocha Jr, Sandra Stroparo, Sérgio Amaral, Teresa Wachowicz, Walter Torres Neto, Wilberth Salgueiro

\section{Conselho Consultivo}

Adalberto Müller (UFF), Álvaro Faleiros (USP), Brunno Vinicius Gonçalves Vieira (Unesp-Araraquara), Fernando Cabral Martins (Universidade Nova de Lisboa), Helena Martins (PUC-Rio), Irene Aron (USP), Isabella Tardin Cardoso (Unicamp), Juliana Perez (USP), Luciana Villas Boas (UFRJ), Márcia Martins (PUC-Rio), Maria Irma Hadler Coudry (Unicamp), Matthew Leigh (University of Oxford), Patrick Farrell (University of California/Davis)

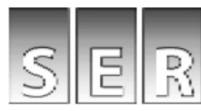

Sistema Eletrônico de Revistas - SER

Programa de Apoio à Publicação de Periódicos da UFPR

Pró-Reitoria de Pesquisa e Pós-Graduação

www.prppg.ufpr.br

o Sistema Eletrônico de Revistas (SER) é um software livre e permite a submissão de artigos e acesso às revistas de qualquer parte do mundo. Pode ser acessado por autores, consultores, editores, usuários, interessados em acessar e obter cópias de artigos publicados nas revistas. O sistema avisa automaticamente, por e-mail, do lançamento de um novo número da revista aos cadastrados. 


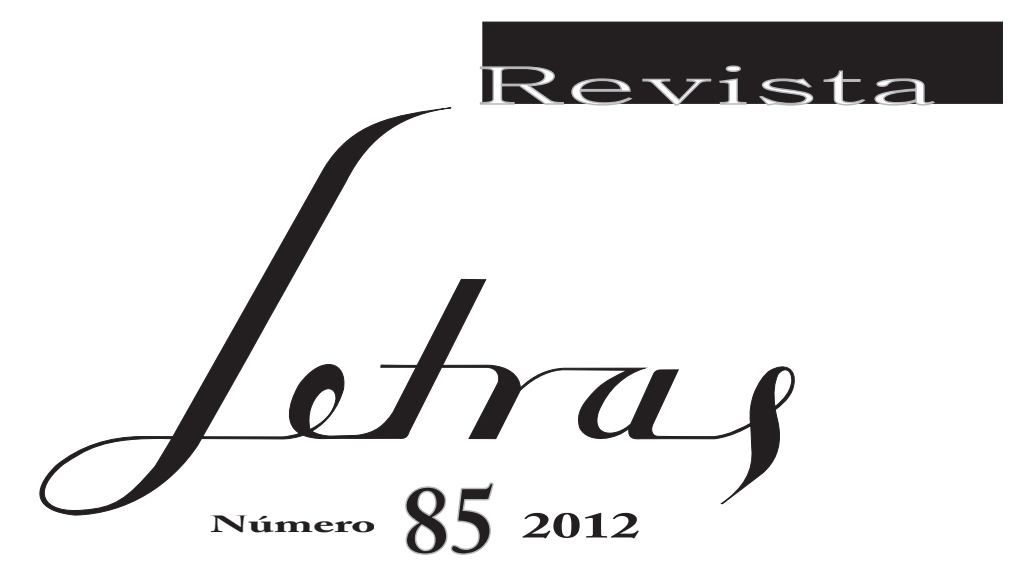

Editora 


\author{
EDITORA UFPR \\ R. João Negrão, $280,2^{\circ}$ andar \\ tel./fax (41) 3360-7487/3360-7486 \\ Caixa Postal 19.029 - 81.531-980 - Curitiba - Paraná - Brasil \\ www.editora.ufpr.br \\ editora@ufpr.br \\ Coordenação editorial: Daniele Soares Carneiro \\ Revisão dos textos em \\ Português: Fabricio Alberto de Oliveira \\ Inglês: Maximiliano Guimarães \\ Projeto Gráfico e Capa: Rachel Cristina Pavim \\ Editoração eletrônica: Artes \& Textos Editora Ltda.
}

A Revista Letras, n. 85 , janeiro a junho de 2012, poderá ser obtida em permuta junto à Biblioteca Central - Caixa Postal 19.051 - 81.531-980 - Curitiba - Paraná - Brasil inter@ufpr.br

Coordenação de Processos Técnicos. Sistema de Bibliotecas, UFPR

\footnotetext{
Revista Letras / Universidade Federal do Paraná, Setor de

Ciências Humanas, Letras e Artes. - n. 21 (1973)-

n. 85
}

\author{
Semestral \\ Continuação de Letras. \\ ISSN 0100-0888 (versão impressa) \\ 2236-0999 (versão eletrônica)
}

1. Linguística. I. Universidade Federal do Paraná.

Setor de Ciências Humanas, Letras e Artes.

\author{
CDD 410.5 \\ CDU 801(05)
}

Série Revista da UFPR, n. 270

ISSN 0100-0888 (versão impressa)

2236-0999 (versão eletrônica)

Ref. 683

\author{
FUNDACÃO \\ ARAUCARI \\ Apoio ao Desenvolvimento Científico \\ e Tecnológico do Paraná \\ PRINTED IN BRAZIL \\ Curitiba, 2012 \\ PEDE-SE PERMUTA \\ WE ASK FOR EXCHANGE
}




\section{Apresentação}

\section{Presentation}

Este número da Revista Letras está com um atraso aproximado de quatro meses, os quatro meses da greve que atingiram as universidades federais entre maio e setembro neste ano de 2012. A greve tinha a pauta salarial, mas também visava a um novo plano de carreira e, principalmente no caso das novas IFES, reivindicava melhores condições de trabalho. Nenhum desses pontos foi contemplado pelo governo.

Historicamente, a mídia costuma tomar como centro da greve a paralisação das atividades didáticas, em particular as de graduação. Ora, todos nós seríamos regiamente bem pagos se as nossas atividades nas IFES se restringissem às nossas horas dentro da sala de aula. Este é sem dúvida o ponto mais visível de nossa atividade, mas está muito longe de ser o único afetado por uma greve. Todas as atividades universitárias ficam prejudicadas, mesmo as invisíveis para a mídia e para a opinião pública em geral, como é o caso das atividades ligadas à pesquisa e à publicação de seus resultados.

Chegamos assim às revistas acadêmicas. Os nossos planos departamentais não contemplam as horas que gastamos emitindo pareceres para as mais diversas revistas das quais tomamos parte como pareceristas. Os nossos Lattes mal têm lugar para registrarmos essa atividade, que raramente conta pontos ou horas inclusive para as nossas famigeradas progressões funcionais. Contudo, ela é o núcleo de toda a maquinaria de publicização de nossos trabalhos. Reconhecendo isso, fizemos o possível para não atolar os colegas durante a greve com pedidos de parecer. Mas não foi possível não fazê-lo após a greve. Queremos por isso agradecer efusivamente a todos os pareceristas que trabalharam em ritmo acelerado para que este número 85 da Revista Letras pudesse vir à luz, mesmo que com algum atraso.

Por outro lado, a Revista Letras passou a ser A2 na última avaliação da Capes, sem dúvida em função da excelência dos artigos que publica, mas também, e principalmente, em função do seu compromisso com a periodicidade. Igualmente em função da periodicidade a Revista Letras ganhou uma pequena ajuda do $\mathrm{CNPq}$ (processo no. 402523/2011-3) para custear os dois números de 2012. A ajuda financeira não é suficiente, mas essa não pode ser uma razão para abandonar o compromisso com relação também ao segundo número de 2012. Novamente, graças ao empenho do Programa de Pós-Graduação em Letras da UFPR (formatando um projeto junto à Funda- 
ção Araucária), dos editores e dos pareceristas, está garantida a publicação eletrônica das duas revistas ainda a tempo de entrarem para o Coleta Capes dos Cursos de Pós-graduação que abrigam autores e pareceristas.

A Revista Letras tem o prazer de apresentar ao leitor dois textos na área de estudos linguísticos, um sobre a construção da autoria na reescrita de textos e um segundo sobre a autonomia nas práticas colaborativas em teletandem. $\mathrm{Na}$ área de estudos literários, são quatro os textos, versando sobre diferentes autores: o primeiro discute a obra de Manoel de Barros, o segundo fala sobre Agualusa, o terceiro se debruça sobre a escritura de Maurice Blanchot e o último apresenta uma análise de uma peça inédita de Julia Lopes de Almeida. Finalmente, a Revista Letras contempla seus leitores com um dossiê na área da tradução, intitulado "Abordagens Multidisciplinares da Tradução", organizado por Maurício Mendonça Cardozo e Maria Clara Castellóes de Oliveira. Trata-se de um conjunto de oito textos versando sobre os problemas contemporâneos da tradução, discutidos pelos maiores nomes da área da tradução no Brasil, que integram o grupo de abordagens multidisciplinares da tradução.

Nós temos certeza de que você, leitor, vai se deliciar! Boa leitura!

Maria Cristina Figueiredo Silva

Marcelo Paiva

Maximiliano Guimarães 
Número 85, jan./jun. 2012 - Editora UFPR

Curitiba - Paraná - Brasil

\section{SUMÁRIO / SUMMARY}

\section{Estudos Linguísticos / Linguistic Studies}

A construção da autoria na reescrita de textos: efeitos da interação professor-aluno

11 The construction of authorship in the rewriting of texts:

effects of interaction between teacher and student

Evandro Gonçalves Leite e Regina Celi Mendes Pereira

29 Autonomia e reflexão nas práticas telecolaborativas em teletandem Autonomy and reflection in telecollaboration practices in teletandem Daniela Nogueira de Moraes Garcia

\section{Estudos Literários / Literary Studies}

O lugar da subjetividade: a importância do lugar na identidade ficcional de Manoel de Barros

53 The place of subjectivity: the importance of place in the fictional identity of Manoel de Barros

Waleska Rodrigues de Matos Oliveira Martins e Sérgio Ricardo Oliveira Martins

O viajante do continente imaterial: Agualusa, o relato de viagem e lusofonia

71 The traveller of the immaterial continent: Agualusa, the travel reporting and lusophony

Aulus Martins

Desdobramento do neutro e (o fora desejável): a escritura (fragmentária) do desastre, de Maurice Blanchot

83 Unfolding the neutral and (the desirable outside): the (fragmentary) writing of the disaster, by Maurice Blanchot Amanda Mendes Casal e Éclair Antonio Almeida Filho

Nobreza sem brasão: uma análise sobre a peça inédita "A Senhora Marquesa", de Júlia Lopes de Almeida

99 Unrenowned nobility: some reflections on the unpublished play "A Senhora Marquesa" [The Lady Marchioness] by Júlia Lopes de Almeida Michele Asmar Fanini 


\section{Dossiê: Abordagens multidisciplinares da Tradução / Multidisciplinary approaches to translation}

131 Apresentação

131 Presentation

Maurício Mendonça Cardozo e Maria Clara Castellões de Oliveira

Tradução e perspectivismo

135 Translation and perspectivism

Helena Franco Martins

A contribuição de filósofos judaicos para a ética do traduzir

151 The contribution of Judaic philosophers to the ethics of translation Maria Clara Castellões de Oliveira

Revisitando os clássicos: Schleiermacher, numa ótica Wittgensteiniana

163 Revisiting the classics: Schleiermacher under Wittgenstein's view Paulo Oliveira

Tradução como transformação: liminaridade, incondicionalidade e a crítica da relação tradutória

181 Translation as transformation: liminality, unconditionality and the criticism of the translating relation

Mauricio Mendonça Cardozo

Mais ou menos negra? Questões de negritude, tradução e a poesia de Harryette Mullen

203 More or less black? Blackness issues, translation and the poetry of Harryett Mullen

Lauro Maia Amorim

Brasiliana e Reconquista do Brasil: projetos editoriais de traduções

219 Brasiliana and Reconquista do Brasil: editorial translation projects Cristina Carneiro Rodrigues

A prática contemporânea de tradução com auxílio de sistemas de memórias e os limites da responsabilidade do tradutor

231 Contemporary translation practice aided by translation memory systems and the limits of the translator's responsability

Érika Nogueira de Andrade Stupiello

Intérprete, eu serei

243 Interpreter, I will be

Márcia Atálla Pietroluongo 